\title{
Prevalence of caprine tuberculosis in Mid- Rift valley area of Oromia, Ethiopia
}

\author{
Ketema Tafess ${ }^{1 *}$, Fufa Dawo ${ }^{2}$, Teshale Sori ${ }^{2}$ and Gobena Ameni ${ }^{3}$ \\ ${ }^{1}$ Faculty of Veterinary Medicine, Gondar University, P. O. Box 196, Gondar, Ethiopia. \\ ${ }^{2}$ Faculty of veterinary medicine, Addis Ababa University, P. O. Box 34, Debreziet, Ethiopia. \\ ${ }^{3}$ Aklilu Lemma Institute of Pathobiology, Addis Ababa University, P. O. Box 1176, Addis Ababa, Ethiopia.
}

Accepted 10 March, 2011

\begin{abstract}
A cross sectional study of caprine tuberculosis was conducted on randomly selected 630 goats at, Adami Tulu Agricultural Research Centre and, smallholder farmers found around the research centre from December 2005 to June 2006. Single intradermal tuberculin test, post mortem examination of suspected goats and bacteriological culture of the pathogen were carried out to confirm the pathogen. Taking the cut off value at $3.5 \mathrm{~mm}$, there was significant difference $(p<0.05)$ in prevalence of caprine tuberculosis between Adami Tulu Agricultural Research Centre and households around Adami Tulu town (3.1 and 9.6\%, respectively). The individual animal prevalence was not affected by sex, age, and flock size ( $p>0.05)$. Goats under smallholder conditions are 3.1 times at risk of acquiring mycobacterial infection than those under on-station condition. Gross tuberculous lesions were detected in two of the eight tuberculin positive (suspected) goats that were slaughtered for confirmation of tuberculosis lesion, sampling and culture for further confirmation of mycobacterial growth. Mycobacterial growth and acid fast bacilli were confirmed in those goats with gross tuberculosis lesions. In conclusion, this study showed the occurrence of tuberculosis in goats in Adami Tulu area. Further studies and confirmation of mycobacterial species and strains which infect goats and probably humans are necessary, especially in areas that consume raw goats' milk like pastoral and agro-pastoral areas so that at least awareness, concerning the transmission of the disease from goats' milk and meat can be created.
\end{abstract}

Key words: Caprine tuberculosis, goats, prevalence, tuberculin test, post mortem lesion.

\section{INTRODUCTION}

Tuberculosis (TB) is an infectious, granulomatous, contagious, and chronic debilitating disease caused by acid fast bacilli of the genus Mycobacterium (WHO, 1998). Although, commonly defined as a chronic debilitating disease, TB occasionally assumes acute, rapidly progressive courses. It is a major health problem worldwide and a single leading cause of human mortality due to infectious disease.

Mycobacterium tuberculosis (M. tuberculosis) is the primary cause of human tuberculosis, but some cases of human TB are caused by Mycobacterium bovis ( $M$. bovis). M. bovis is a member of the $M$. tuberculosis

\footnotetext{
*Corresponding author. E-mail: Ketema_taf@yahoo.com.
}

complex (MTBC) that comprises the closely related Mycobacterium species: $M$. tuberculosis, $M$. bovis, $M$. bovis BCG strain, $M$. africanum, M. microti and $M$. canetti (Devendera, 1992; Pritchard et al., 1975). Despite this close relationship, the species of MTBC show a large variability in their phenotypic properties, epidemiology and importance for human TB and differ slightly in their evolutionary history (Brosch et al., 2002). In contrast to $M$. tuberculosis and $M$. africanum with their natural habitat in humans, $M$. bovis has a broad host range and cause TB in wide range of domestic and wild animals and also in humans (O'Reilly and Daborn, 1995).

$M$. tuberculosis is the most frequent causes of human morbidity and the leading cause of human mortality worldwide, but human cases can also be due to $M$. bovis that has two subspecies: M. bovis subspecies caprae and 
M. bovis subspecies bovis. The epidemiology of TB due to $M$. bovis is very complex and include the transmission within and between domestic and wildlife, as well as between animals and humans and/or vice versa (O'Reilly and Daborn, 1995). The importance of $M$. bovis in human TB has been dramatically decreased after the introduction of effective control measure around the last century in many developed countries (O'Reilly and Daborn, 1995). However, M. bovis is responsible for greater proportion of animal and human tuberculosis in several developing countries. In many developing countries especially in Africa, where $M$. bovis infection has been reported in a wide range of animal species, it is possible to speculate its wide spread and zoonotic potential. Some human TB cases in Africa are becoming multiple drug resistant and are threatening the world seriously.

The influence of high rate of human immunodeficiency virus/AIDS in several developing countries on TB patients found in these regions is also an issue of considerable interest that has not yet been addressed. Given the fact that HIV/AIDS and $M$. bovis transmission are high in Africa, with $90 \%$ of the population of Africa living in areas where neither pasteurization of milk nor BTB control programs occur and up to one in ten adults are infected with HIV (Cosivi et al., 1998). The association between these two diseases is of particular concern on this continent (Cosivi et al., 1998; Liss et al., 1994) that in turn, is exacerbated by poor living standard and poor hygienic conditions prevailing in the region. In addition, the emergence of drug resistant strains of mycobacteria initially in South Africa and its recent spread in many developing and developed countries imposes another burden to the World Health Organization that can be contributed by the tuberculosis acquired from caprine or other animal species.

In the past, TB has been considered rare in goats and it was thought that this species is naturally immune to tuberculosis; however, long time ago, it was reported that goats possesses no particular resistance to the disease (Pritchard et al., 1975). Tuberculosis in goats has been reported from France, Italy, Great Britain, German, USA, Africa, India, Australia, New Zealand (Wayne et al., 1986) and very recently in an outbreak form from Greece (Ikonomopoulos et al., 2006). According to reports from France and Germany, the strain of $M$. bovis isolated from goats is, $M$. bovis subspecies caprae that are, unlike $M$. bovis subspecies bovis pyrazinamide (PZA) sensitive (Niemann et al., 2002). This sensitivity criterium is used to differentiate the two in the laboratory.

From Africa, according to OIE report (OIE, 2000), tuberculosis in goats was observed in slaughter houses in Coted'Ivoire. Furthermore, Carmicheal (1989) isolated bovine strain from goats in Zambia. In Ethiopia, studies conducted in different abattoirs (Hiko, 2005; Nigussie, 2005) that were supported by mycobacterial culture, showed occurrence of tuberculosis in goats, but those studies did not use intradermal tests and cannot help establish the magnitude and distribution of the disease in goats. Therefore, this study was formulated to determine the prevalence of caprine tuberculosis in Adami Tulu and its surroundings so that it can be used as a base for further study in live goats and humans.

\section{MATERIALS AND METHODS}

\section{Description of the study area}

The study was conducted in Adami Tulu Jiddo Kombolcha district, located in East Showa zone of the Oromia regional state from October 2005 up to April 2006. The zone covers the largest part of the mid-rift valley, and the study area is located about $165 \mathrm{~km}$ south of Addis Ababa (Figure 1).

The altitude of the area ranges from 500 to $1800 \mathrm{~m}$ above sea level. The area has an erratic, unreliable and low rainfall. The average annual rainfall of the area is between 500 and $900 \mathrm{~mm}$. The rainfall is sometimes bimodal with short rainy season from March to May and long rainy season from June to September, followed by the dry season from October to February. The area has average maximum and minimum annual temperature of 27.2 and $12.7^{\circ} \mathrm{C}$ respectively and a relative humidity of $60 \%$ (Ebro et al., 1998).

The total human population of Adami-Tulu Jiddo kombolcha district is about 111,926 out of which, $72 \%$ live in the rural area while $28 \%$ are urban dwellers. The total land area of the district is estimated to be about 75,223 ha, of which, 36,661 ha is used for crop production, whereas, 17,113 ha is used for grazing. According to census data collected by district's agricultural office in $2005 / 2006$, there are about 189,870 cattle, 85,365 goats, 11,330 sheep, 17,356 donkeys, 256 mules, 1,442 horses and 80,270 poultry in the study area. The census indicates that goats are the most important animal species in the area, next to cattle.

\section{Study animals and sampling}

The study was conducted on 630 goats, of which 193 goats were from Adami Tulu Agricultural Research Centre and 437 goats were from different smallholder farmers or peasant association from Adami Tulu Jido Kombolcha district. The predominant goat breeds in the study area are Arsi-Bale goats (FARM-Africa, 1996) which are managed under extensive production system.

Traditional housing and grazing of natural pasture are the predominant husbandry practices. According to our observation, farmers who own more than five goats keep them in barns while those who own less than five goats keep them in their own houses.

\section{Single intradermal tuberculin testing}

Single intradermal tuberculin test, previously reported in goats, was used for the study (O'Reilly and Daborn, 1995). The test has been effectively used for the diagnosis of tuberculosis in goats and has sensitivity that ranges from 82 to $93.8 \%$ (O'Reilly and Daborn, 1995). Briefly, the middle neck of each of the study animals was shaved, the thickness of the site was measured with callipers, and $0.1 \mathrm{ml}$ of bovine tuberculin (Bovituber PPD, Symbiotic Corporation, France) containing $20,000 \mathrm{IU} / \mathrm{ml}$ of purified protein derivative (PPD) was injected into the dermis of each animal.

Three days (72 h) after injection, the site was re-measured to assess the increments or any change in skin thickness. Since there is no standardized cut off value for goats as in the case of cattle, the cut of value was tentatively fixed to $3.5 \mathrm{~mm}$ in this 


\section{AGRO ECOLOGICAL ZONES OF EAST SHOA ZONE}

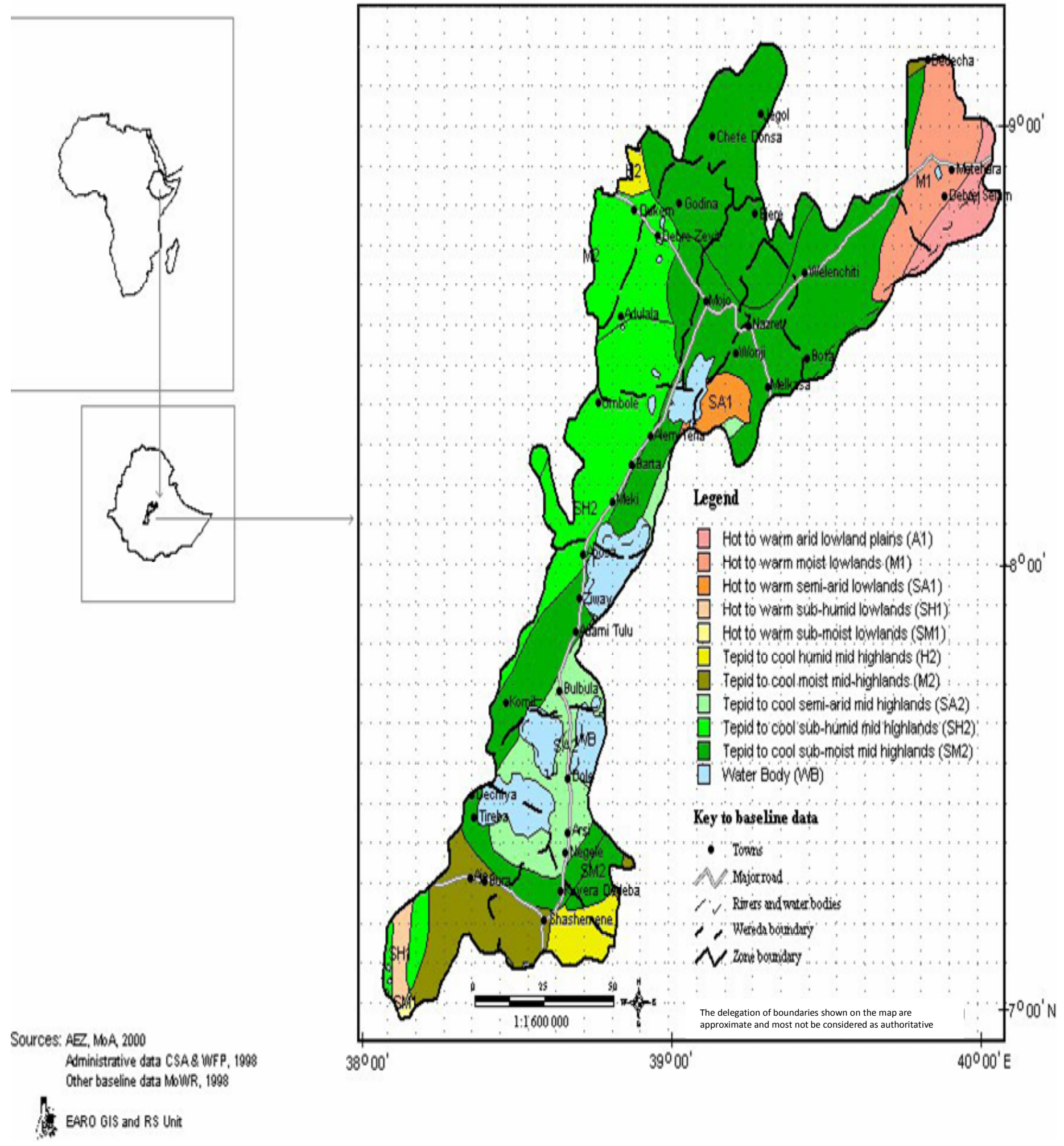

Figure 1. Arrow indicates the study area.

study. When the swelling was equal or less than $2 \mathrm{~mm}$, between 2 $\mathrm{mm}$ and $3.5 \mathrm{~mm}$, and equal to or greater than $3.5 \mathrm{~mm}$, individual result was considered as negative, doubtful and positive, respectively. 
Table 1. Association between different risk factors and prevalence of tuberculosis in goats at centre.

\begin{tabular}{lcccc}
\hline Risk factor & Tested number & Positive no (\%) & $\chi^{2}$ & P -value \\
\hline Age in years & & & & \\
$<21 / 2$ & 20 & $0(0)$ & 0.72 & $\mathrm{P}>0.05$ \\
$\geq 21 / 2$ & 173 & $6(3.5)$ & & \\
Sex & & & & \\
Male & 73 & $1(1.4)$ & \multirow{2}{*}{1.28} & $\mathrm{P}>0.05$ \\
Female & 120 & $5(4.2)$ & & \\
\hline
\end{tabular}

\section{Post mortem examination}

Post mortem examination was carried out on eight tuberculin positive goats (increment in skin thickness $>3.5 \mathrm{~mm}$ ) for detection of tuberculosis lesions and confirmation of tuberculosis in reactor goats at Adami Tullu Agriculture Research Centre post-mortem house. The organs examined include lymph nodes (bronchial, mediastinal, mesenteric and hepatic), lungs, liver, intestine and kidney. These organs were inspected, palpated and then sliced finely for further investigation.

\section{Isolation of Mycobacteria}

The tissue specimens for culture were collected from eight slaughtered goats into sterile universal bottles in saline, and shipped immediately to Aklilu Lemma Institute of Pathobiology Laboratory in cold chain for isolation of Mycobacteria according to WHO (1998). The tissues were homogenized using mortar and pestle. The homogenate was decontaminated with $4 \%$ sodium hydro-oxide $(\mathrm{NaOH})$ for $15 \mathrm{~min}$ with intermittent shaking. The homogenate was then centrifuged at $3000 \mathrm{rpm}$ for $10 \mathrm{~min}$. The supernatant was discarded while the sediment was neutralized with $1 \%$ hydrochloric acid (HCL) with phenol red as indicator. Neutralization was achieved when the color of the suspension underwent change from purple to yellow. After neutralization, $0.1 \mathrm{ml}$ of the suspension from each tissue sample was spread on the slants of Lowenstein-Jensen (LJ) medium. Each tissue sample was inoculated into duplicates of LJ media, one with sodium pyruvate and the other with glycerol. The cultures were incubated at $37^{\circ} \mathrm{C}$ in a slant position for one week and in upright position for 10 weeks with weekly observation for mycobacterial growth. Whenever colonies were seen, sub-culturing and Ziehl-Neelson staining were performed to confirm the presence of acid fast bacilli.

\section{Lateral flow assay (chembio rapid test)}

Tuberculosis is a spectral disease with predominantly cellular response during early and intermediate disease stages that are complemented, and in severe cases displaced by humoral immune response in the later stage of the disease (Vitacco et al., 1991). Humoral responses to mycobacteria were found to be strongly boosted after tuberculin skin testing. Blood samples for serum separation were collected from jugular vein of eight goats' primarily positive for SID tuberculin test. A rapid immuno-chromatographic assay, VetTB STATPAK test, which was developed by Chembio Diagnostic Systems, Inc., Medford, N.Y., to detect antibodies of three isotopes ( $\lg M, \lg G$, and $\lg A)$ against mycobacterial antigens was used for the rapid serological assay. This test was performed following the procedure described by Waters et al. (2006). Accordingly, $30 \mu \mathrm{l}$ of serum and 3 drops of sample diluents were added sequentially to the sample pad. As the diluted test sample migrates to the conjugate pad, the latex particles conjugated to antigen, bind antibody, if present, thus, creating a colored immune complex. Driven by capillary forces, this complex flows laterally across the nitrocellulose membrane impregnated with specific antigen and binds to immobilized antigen, producing a visible blue band in the test area of the device. In the absence of specific antibody, no band is visible in the test window. The liquid continues to migrate along the membrane, producing a similar blue band in the control area of the device, irrespective of the presence of specific antibody in the test sample, demonstrating that the test immuno-reagents are functional properly. Test results were read at 20 min and interpretation of the result was done on the basis of the intensity of the band in test area. Accordingly, when there was no visible band, weak band, moderate or strong band, the test was considered as negative (0), weak positive $(+)$, moderately positive $(++)$, or strongly positive $(+++)$, respectively.

\section{Data analysis}

Individual animal prevalence was defined as the number of reactor goats out of 100 tested animals and expressed in percentage. The comparison of prevalence between different age, sex and herd size was done using chi-squire $\left(Z^{2}\right)$ test. Odds ratio $(\mathrm{OR})$ was calculated to assess strength of association of prevalence with explanatory variables such as age, sex and herd size. A p-value of less than 0.05 was considered statistically significant (SPSS, 2003).

\section{RESULTS}

\section{Prevalence based on single intradermal test}

\section{At the centre}

All goat flocks were considered as one herd or flock and individual animal prevalence of $3.1 \%$ was recorded from goats kept at Adami Tullu Agricultural Research Centre. When animals with doubtful reaction were considered as positive, the prevalence became $26.18 \%$. There was no statistically significant difference in prevalence of the disease among the age groups $\left(Z^{2}=0.72, \mathrm{P}>0.05\right)$ and sex groups $\left(Z^{2}=1.28, \mathrm{P}>0.05\right)$ (Table 1$)$.

\section{Prevalence at household level}

Individual animal prevalence of $9.6 \%$ was recorded when 
Table 2. Association between different risk factors and prevalence of tuberculosis in goats at the household level.

\begin{tabular}{lcccc}
\hline Risk factor & Test number & Positive no (\%) & $\chi^{2}$ & P-value \\
\hline Age in years & & & & \\
$<21 / 2$ & 63 & $10(15.9)$ & 3.32 & $\mathrm{P}>0.05$ \\
$\geq 21 / 2$ & 374 & $32(8.5)$ & & \\
Sex & & & & \\
Male & 112 & $14(12.5)$ & 1.45 & $\mathrm{P}>0.05$ \\
Female & 325 & $28(8.6)$ & & \\
Flock size & & & & \\
$1-10$ & 73 & $9(12.3)$ & 5.52 & $\mathrm{P}>0.05$ \\
$10-20$ & 92 & $3(3.3)$ & & \\
$>20$ & 272 & $30(11.0)$ & & \\
\hline
\end{tabular}

Table 3. Overall comparison of caprine tuberculosis by site, sex and age.

\begin{tabular}{lcccc}
\hline Risk factor & Test number & Positive no (\%) & $\chi^{2}$ & P-value \\
\hline Age & 83 & $10(12.0)$ & & \\
$<21 / 2$ & 547 & $38(6.9)$ & 2.66 & $\mathrm{P}>0.05$ \\
$\geq 21 / 2$ & & & & \\
Sex & 187 & $15(8.0)$ & & \\
Male & 443 & $33(7.4)$ & 0.06 & $\mathrm{P}>0.05$ \\
Female & & & & \\
Site & 193 & $6(3.1)$ & & \\
Centre & 437 & $42(9.6)$ & 8.04 & $\mathrm{P}<0.01$ \\
Farmer & & & & \\
\hline
\end{tabular}

doubtful animals were considered as negative and the prevalence became $38.5 \%$ when doubtful animals were considered as positive. As shown in Table 2, no statistically significant difference was recorded in prevalence among different groups of age $\left(z^{2}=3.32, p>0.05\right)$, sex $\left(z^{2}=1.45, \mathrm{p}>0.05\right)$ and flock size $\left(z^{2}=5.52, \mathrm{p}>0.05\right)$.

General comparison of caprine tuberculosis of all tested goats indicated that there was significant difference between on-station (Adami Tullu Research Centre) and on-farm goats $(\mathrm{p}<0.01)$ but no significant difference in skin reactivity between ages and sex (Table $3)$.

\section{Post mortem examination}

The results of post mortem examination revealed the presence of gross tuberculous lesions in the lung and intestine in two tuberculin reactor goats. The lesion was typically Miller seed like, small, calcified tubercles approximately 0.5 to $2 \mathrm{~cm}$ and when incised, yellowishwhite caeseous material was observed. Localized lesion in the lung and bronchial lymph node was seen in one goat, whereas, other lesions were encountered in intestine in the other goats. Lesions in the lung were bigger in size and undergoing calcification (no pus). No gross post mortem lesion was observed in other sacrificed goats.

\section{Mycobacterial culture}

Mycobacterium growth on pyruvate enriched LJ media and acid fast bacilli were confirmed in two of the suspected goats with gross lesions of tuberculosis.

\section{Serum immunoglobulin detection}

Although serum immunoglobulin detection was applied to all eight serum samples tested, none of them was found to be positive or reacting. 


\section{DISCUSSION}

TB in goats has been traditionally considered as minor problem and at this time, it is not under control policies in many countries. However, countries like France, Germany, U.S.A., Australia, Great Britain, India, Coted'Ivoire, Zambia, have reported tuberculosis in goat (O'Reilly and Daborn 1995). Hiko (2005) and Nigussie (2005) have shown the importance of the disease at different abattoirs in Ethiopia. The present study has also showed the occurrence of tuberculosis in goats at Adami Tulu area, especially in goats kept by smallholder farmers. The presently recorded prevalence was almost similar to previous studies (Hiko, 2005; Nigussie, 2005). Prevalence of goat tuberculosis at the house hold level is higher than that recorded in the same study area, but in Adami Tulu Agricultural Research Centre. Smallholder farmers usually keep goats with cattle during the day time and with young cattle during the night. An assumption to explain this fact is that, the area is known for goat production and they keep large number of goats in barn with young cattle at night. This increases the risk of transmission of the disease from infected cattle to goat, and from goat to goat. It was reported that goats acquire tuberculosis when they have close contact with cattle and share pasture with infected cattle (Radostits et al., 2000). Moreover, specificity of SID tuberculin test is low as it can cross react with related mycobacterium like $M$. avium and M. paratuberculosis (Quinn et al., 2000) which could also infect goats. Six reactor goats did not have gross lesions and were also culture negative. This is because SID tuberculin test responds positively not only to infection with $M$. bovis but also to infection with other organisms like Nocardia farcinicus (Radostits et al., 2000). Thus, the occurrence of non visible lesions reactors is not uncommon. In general, the prevalence recoded in this study is still lower than that recorded in feral goat in New Zealand (Sanson, 1988). The relative importance of rearing goats has increased because of the decline of land holding and shrinkage of grazing land. People in the low land, including in Adami Tulu area, consume goat's raw milk, which favors the transmission of tuberculosis from goats to human beings. The present study showed that the occurrence of tuberculosis in goat in the area. Therefore, further study on the epidemiology and zoonotic significance of TB of goats and development of standard diagnostic tools for TB in goats is important. In addition, public awareness creation, of the need of boiling goats' milk before consumption is very important.

\section{ACKNOWLEDGEMENTS}

We would like to acknowledge members of Adami Tulu Agricultural Research Centre in general, animal health research division in particular, for their special contribution during field work and over all study.

\section{REFERENCES}

Brosch R, Gordon SV, Marmiesse M, Brodin P, Buchrieser C, Eiglmeier K, Garnier T, Gutierrez C, Hewinson G, Kremer K, Parsons LM, Pym AS, Samper S, van Soolingen D, Cole ST (2002). A new evolutionary scenario for the Mycobacterium tuberculosis complex. Proceed. Natl. Acad. Sci., USA, 99: 3684-3689.

Cosivi O, Grance JM, Daborn CJ, Raviglione MC, Fujikura J, Cousins D, Roblnso RA, Huchzemener HF, Decantor I, Meslin FX (1998). Zoonotic tuberculosis due to Mycobacterium bovis in developing countries. Emer. Infect. Dis., 4: 1-7.

Devendera C (1992). Goat and Rural property. In: pre-conference proceedings: plenary papers and invited lectures International conference on goats, 2-8 march 1992, New Delhi, pp. 6-25.

Ebro A, Eticha G, Hussen A (1998). Thirty years of research experience of Adami Tulu Agricultural Research Centre, Oromia Agricultural Development Bureau. Bulletin, 1: 1-16.

FARM-Africa (1996). Goat types of Ethiopia and Eritrea. Physical description and managements. Published jointly by FARM-Africa, London, UK, and ILRI, Nairobi, Kenya. p. 76.

Hiko A (2005). Preliminary study on caprine tuberculosis in Modjo Export Abattoir. DVM Thesis, Faculty of Veterinary Medicine, DebreZeit, Ethiopia.

Ikonomopoulos J, Aranaz A, Balaskas C, Sechi L, Gazouli M (2006). Outbreak of acute tuberculosis in a goat herd; first report of Mycobacterium caprae isolation in Greece Online J. Vet. Res., 10: $108 \quad-\quad 115$ http://www.comcen.com.au/ journals/mycobacteriaabs2006. htm Accessed on July 17, 2007.

Liss GM, Wong L, Kittle DC, Salmor A, Naus M, Martiquet P, Misener CR (1994). Occupational exposure to Mycobacterium bovis infection in deer and elk in Ontario. Can. J. Pub. Health, 85: 326-329.

Niemann S, Richter E, Rusch-Gerdes S (2002). Bio-chemical and genetic evidence for the transfer of Mycobacterium tuberculosis subspecies caprae. Int. J. Evol. Microbiol., 52: 433-436.

Nigussie T (2005). Preliminary study on Tuberculosis in small ruminants slaughtered at HELIMEX export abattoir. DVM, Thesis Faculty of Veterinary Medicine, Debre-Zeit, Ethiopia.

O'Reilly LM, Daborn CJ (1995). The epidemiology of Mycobacterium bovis infections in animals and man: A review. Tuber. Lung Dis., 76: $1-46$.

OIE (2000). Bovine tuberculosis. In Manual of Standard Diagnostic Tests and Vaccine. OIE.

Pritchard DG, Francis OA, Gripp R, Harding RB, Jones EP, Minten CMc, Goven McP (1975). An abattoir surveys of bovine tuberculosis in the karamu region of Uganda. B. Vet. J., 131: 120-131.

Quinn PJ, Carter MC, Markey B, Carter GP (2000). In: Clinical Veterinary Microbiology. London. Wolf publishing, p. 156.

Radostits OM, Gay CG, Blood DC, Hinchclift KW (2000). Bovine tuberculosis. In: Deborah Rusella (edition): A textbook of disease of cattle, sheep, goats and horse, 9th ed. London, Harcourt Publishers Limited, pp. 909-919.

Sanson RL (1988). Tuberculosis in goats. Surveillance, 15: 7- 8.

SPSS (Statistical package for social science) (2003). SPSS for Windows, Version 12.

Waters WR, Palmer MV, Thacker TC, Bannantine JP, Vordermeier HM, Hewinson RG, Greenwald R, Esfandiari J, McNair J, ollock JM, Andersen P, Lyashchenko KP (2006). Early antibody responses to Mycobacterium bovis infection in cattle. Clin. Vacc. Immunol., 13: 648-654.

Vitacco V, Lopez B, Dekantory IN, Barrera L, Errico F, Nader A (1991). Reciprocal cellular and hummoral immune response in bovine tuberculosis. Rec. Vet. Sci., 50: 365-367.

WHO (1998). Laboratory services in tuberculosis control. Global tuberculosis program. World Health Organization (WHO). Geneva, Switzerland. 